\title{
Lactoferricin treatment decreases the rate of cell proliferation of a human colon cancer cell line
}

\author{
C. Freiburghaus, ${ }^{* 1}$ B. Janicke, ${ }^{*}$ H. Lindmark-Månsson,† S. M. Oredsson, $\ddagger$ and M. A. Paulsson* \\ *Department of Food Technology, Engineering and Nutrition, Lund University, PO Box 124, 22100 Lund, Sweden \\ †Swedish Dairy Association, Scheelevägen 17, 22370 Lund, Sweden \\ łDepartment of Cell and Organism Biology, Lund University, Helgonavägen 3B, 22362 Lund, Sweden
}

\section{ABSTRACT}

Food components modify the risk of cancer at a large number of sites but the mechanism of action is unknown. In the present investigation, we studied the effect of the peptide lactoferricin derived from bovine milk lactoferrin on human colon cancer CaCo-2 cells. The cells were either untreated or treated with $2.0,0.2$, or $0.02 \mu M$ lactoferricin. Cell cycle kinetics were investigated with a bromodeoxyuridine DNA flow cytometric method. The results show that lactoferricin treatment slightly but significantly prolonged the S phase of the cell cycle. Lactoferricin treatment lowered the level of cyclin E1, a protein involved in the regulation of genes required for $\mathrm{G}_{1} / \mathrm{S}$ transition and consequently for efficient $\mathrm{S}$ phase progression. The slight prolongation of the $\mathrm{S}$ phase resulted in a reduction of cell proliferation, which became more apparent after a long treatment time.

Key words: CaCo-2, cancer, cell cycle kinetics, lactoferricin

\section{INTRODUCTION}

Milk consumption has been linked, in several epidemiological studies, to a reduced risk of numerous cancers, among them colon cancer (Cho et al., 2004; World Cancer Research Fund/American Institute for Cancer Research, 2007). In addition, animal studies have indicated anticancer activities of different milk components (Gill et al., 2000; Perdigon et al., 2002; Wakabayashi et al., 2006). Bovine milk, as well as human milk and milk from most other mammals, is very rich in bioactive factors that provide the newborn protection from various infections (Gill et al., 2000; Korhonen and Pihlanto, 2006). Milk proteins and peptides have been shown to exert different regulatory activities of physiological importance, affecting the digestive, cardiovascular, im-

Received October 29, 2008.

Accepted January 21, 2009.

${ }^{1}$ Corresponding author: catja.freiburghaus@food.lth.se mune, and nervous systems (Korhonen and Pihlanto, 2006).

Among the bioactive proteins with potential to lower cancer incidence is bovine lactoferrin (Lf) (Van Belzen, 2002; Min and Krochta, 2005). Lactoferrin, a whey protein with a molecular weight of approximately 80 $\mathrm{kDa}$, was first identified in cow's milk in 1939 (Levay and Viljoen, 1995). Lactoferricin (Lfcin), a peptide released from Lf by acid-pepsin hydrolysis in the gut (Bellamy et al., 1992), has also been shown to exert anticancer activity (Wakabayashi et al., 2003; Mader et al., 2007). Lactoferricin is a cationic and amphiphatic peptide containing amino acid residues 17 to 41 of $\mathrm{Lf}$ and has a molecular weight of 1,545 Da. The amount of Lfcin detected in the gastric content of humans was $16.9 \pm 2.7 \mu \mathrm{g} / \mathrm{mL}(10.9 \pm 1.7 \mu M)$ about $10 \mathrm{~min}$ after ingestion of Lf equivalent to $20 \mathrm{~L}$ of milk, giving a molecular concentration equivalent to $4.5 \%$ of the ingested Lf (Kuwata et al., 1998). A study demonstrated that more than $60 \%$ of administered bovine Lf survived passage through the adult human stomach and entered the small intestine in an intact form (Troost et al., 2001). Intact and partly intact bovine Lf and bovine Lfcin are likely to exert various physiological effects in the digestive tract. Other evidence suggests that orally or subcutaneously administrated Lfcin possesses potent in vivo activity against cancer cells, inhibiting metastasis, angiogenesis, and tumor growth in mice (Yoo et al., 1997).

In the process of cell proliferation, the dividing cell goes through a phase of growth followed by a phase of division - the cell cycle (Baserga and Wiebel, 1969; Figure 1). During the Gap $1\left(\mathrm{G}_{1}\right)$ phase, the cell prepares for DNA synthesis by general growth. The chromosomes are duplicated during the DNA synthesis $(\mathrm{S})$ phase. During the Gap $2\left(\mathrm{G}_{2}\right)$ phase, the cell prepares for cell division ( $\mathrm{M}$ phase). The cell divides during $\mathrm{M}$ phase, and from there, the daughter cells either continue into the $G_{1}$ phase of the next cell cycle or enter the resting state, $\mathrm{G}_{0}$ (Norbury and Nurse, 1992).

Different groups of proteins, called cyclins and cyclindependent kinases (cdk), control progression through 
the cell cycle. Through their ability to form complexes, the cyclins and cdks regulate the various cell cycle phases (Figure 1). The cyclins are synthesized and degraded in a fluctuating manner during the cell cycle, whereas the cdk are constitutively expressed (Johnson and Walker, 1999). Extracellular signal-regulated kinase-1/2 (ERK1/2) is part of a signal transduction pathway that commonly regulates cell proliferation. The pathway is activated by extracellular signals that activate receptor tyrosine kinases, which induce phosphorylation of ERK1/2. The phosphorylated ERK1/2, in turn, activates downstream elements such as transcription factors involved in regulation of the cell cycle (Shaul and Seger, 2007).

A growing knowledge of the effect of diet on health offers new opportunities of cancer prevention through a change in eating habits. Over time, small but recurrent doses of bioactive peptides may prevent the carcinogenic process by decreasing the rate of cell proliferation of normal and precancerous cells; in addition, the growth of cancer cells may be reduced. In the present study, we investigated the effects of bovine Lfcin on cell proliferation and cell cycle progression in the human colon cancer cell line CaCo-2. The results showed that Lfcin prolonged the $\mathrm{S}$ phase of the cell cycle, which resulted in a decreased rate of cell proliferation.

\section{MATERIALS AND METHODS}

\section{Lactoferricin}

The water-soluble bovine Lfcin (L1290, 126K1550, Sigma-Aldrich Co., St Louis, MO) was dissolved in PBS $\left(8 \mathrm{~g} / \mathrm{L} \mathrm{NaCl}, 0.2 \mathrm{~g} / \mathrm{L} \mathrm{KCl}, 1.15 \mathrm{~g} / \mathrm{L} \mathrm{Na}_{2} \mathrm{HPO}_{4}\right.$, $\left.0.2 \mathrm{~g} / \mathrm{L} \mathrm{KH}_{2} \mathrm{PO}_{4}, \mathrm{pH} 7.3\right)$ to give a stock solution of $100 \mu M$, which was sterile-filtered $(0.2 \mu \mathrm{m}$, Bergman Labora, Stockholm, Sweden) before addition to the cell cultures. Aliquots of the stock solution were kept at $-20^{\circ} \mathrm{C}$ until use. The concentrations used will be specified below for each experiment.

\section{Cell Culture}

The CaCo-2 cell line was purchased from American Type Culture Collection (HTB-37, Manassas, VA). Growth medium components were purchased from Biochrom (Berlin, Germany) and tissue plastics from Nunc (Roskilde, Denmark). Cells were grown in RPMI 1640 medium supplemented with penicillin (100 U/ $\mathrm{mL})$, streptomycin $(100 \mu \mathrm{g} / \mathrm{mL})$, nonessential amino acids $(1 \mathrm{mM})$ and $10 \%$ (vol/vol) fetal calf serum (FCS) throughout this study. Cultures were grown in a humidified atmosphere of $95 \%$ air and $5 \% \mathrm{CO}_{2}$ at $37^{\circ} \mathrm{C}$. These conditions were kept unchanged throughout the

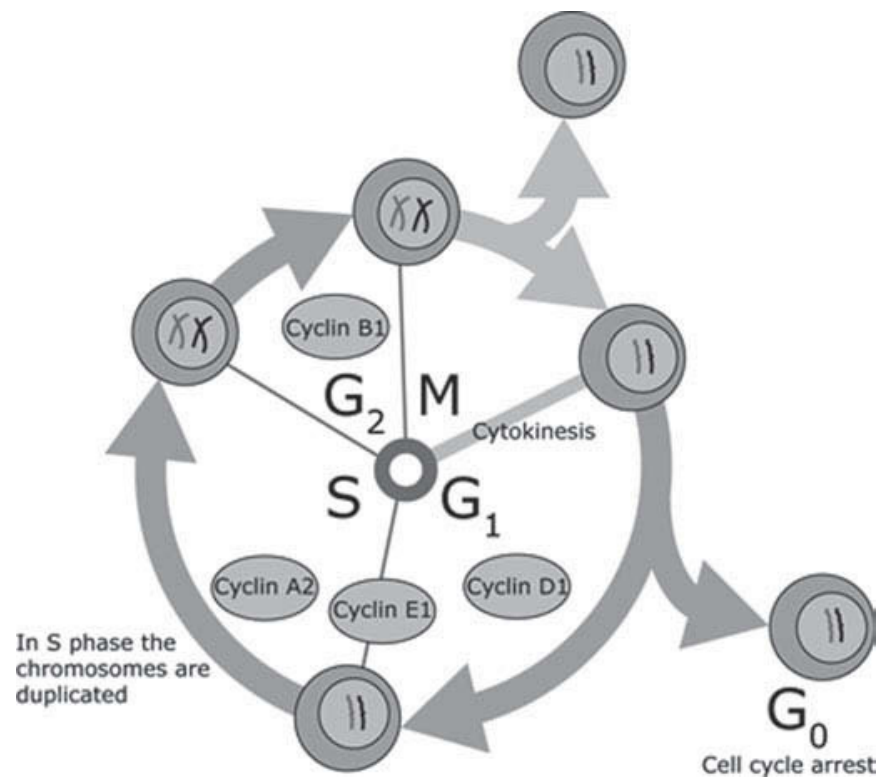

Figure 1. The cell cycle is divided into 4 phases, which are part of the cell's preparation for cell division at the end of mitosis. The chromosomes are duplicated in the S phase. Cyclin D1 is expressed in $\mathrm{G}_{1}$ phase, cyclin E1 is expressed at the $\mathrm{G}_{1} / \mathrm{S}$ transition, cyclin A2 is expressed in the $S$ phase and at the beginning of $G_{2}$ phase, and cyclin B1 is expressed in the $G_{2}$ phase.

study. For the experiments, several replicate cultures, consisting of $2 \times 10^{6}$ cells seeded into $12 \mathrm{~mL}$ of medium in Petri dishes (90 $\mathrm{mm}$ in diameter), were set up.

\section{Cytotoxicity Test}

The 3-(4,5-dimethylthiazol-2-yl)-2,5-diphenyl tetrazolium bromide (MTT) assay was performed as previously described (Holst and Oredsson, 2005). In this assay, MTT is added to the growth medium of the cells and is taken up by living cells via endocytosis and reduced to blue formazan crystals inside the cell via complex I in the mitochondrial respiratory chain. The amount of formazan generated is assumed to be directly proportional to the cell number when using homogeneous cell populations (Mosmann, 1983; Denizot and Lang, 1986; Yamaguchi et al., 2002). In short, cells were seeded in 96-well microplates with a seeding density of 7,500 cells in $180 \mu \mathrm{L}$ of medium. After seeding, the cells were allowed to attach and grow for $24 \mathrm{~h}$ before addition of bovine Lfcin. The concentrations of Lfcin used were $0.002 \mathrm{n} M, 0.02 \mathrm{n} M, 0.2 \mathrm{n} M, 2.0 \mathrm{n} M, 0.02 \mu M$, $0.2 \mu M$, and $2.0 \mu M$. The control cells were exposed to PBS. At 24, 48, and $72 \mathrm{~h}$ of treatment, $20 \mu \mathrm{L}$ of MTT solution (5 mg/mL in PBS; M5655, Sigma-Aldrich Co.) was added to the cells, which were incubated for $1 \mathrm{~h}$ at $37^{\circ} \mathrm{C}$. After removal of the MTT-containing medium, the cells containing insoluble formazan crystals were 
dissolved by addition of dimethyl sulfoxide and the absorbance was monitored. Plates were read on a Labsystems iEMS Reader MF (Labsystems Oy, Helsinki, Finland) at a wavelength of $540 \mathrm{~nm}$. The results are expressed as percentage of control. The experiment was repeated 3 times with 6 wells per concentration in each experiment.

\section{Cell Proliferation}

After seeding, the cells were allowed to attach and grow for $24 \mathrm{~h}$ before addition of Lfcin. The concentrations used were $0.0002,0.02$, and $2.0 \mu M$ Lfcin. The experiment was repeated twice with triplicates of the Petri dishes used for each time point to be analyzed. At each time point, cells were harvested by trypsinization, and the cell number was determined by counting in a hemocytometer (VWR International, West Chester, $\mathrm{PA})$.

\section{Cell Cycle Kinetics}

Bromodeoxyuridine (BrdUrd) is a thymidine analog in which the methyl group has been replaced by a bromine atom. As the bromine atom corresponds well in size with the methyl group, BrdUrd is incorporated into DNA in the same manner as thymidine (Dolbeare et al., 1983). When BrdUrd is added to the growth medium of the cells, only the cells currently synthesizing DNA will incorporate BrdUrd into their genetic material. The labeling stops when the medium containing BrdUrd is removed from the cells. Cells were labeled with a final concentration of $5 \mu M$ BrdUrd (Dako, Glostrup, Denmark) for 30 min at 24,48 , and $72 \mathrm{~h}$ of treatment with 2.0 or $0.02 \mu M$ Lfcin. After the BrdUrd labeling period, the medium was aspirated and the cultures were rinsed twice with RPMI 1640 medium containing $0.5 \%$ FCS $\left(37^{\circ} \mathrm{C}\right)$. The cultures were then further incubated with complete medium $\left(37^{\circ} \mathrm{C}\right)$ that contained the same addition of PBS or Lfcin as before BrdUrd labeling. Cells were harvested by trypsinization at 0 and $5 \mathrm{~h}$ post-labeling for one experiment and at $0,4,6,8,10$, and $12 \mathrm{~h}$ post-labeling for more extensive studies of cell cycle kinetics. Cells were pelleted by centrifugation at $700 \times g$ for $10 \mathrm{~min}$, resuspended, and fixed in ice-cold $70 \%$ ethanol. The samples were then stored at $-20^{\circ} \mathrm{C}$ until analysis. The experiment was repeated twice with triplicates of the Petri dishes used for each time point to be analyzed.

\section{Flow Cytometric Analysis of BrdUrd and DNA Contents}

The staining of DNA and BrdUrd has been described in detail (Fredlund et al., 1994). In short, to allow ac- cess to BrdUrd in DNA of monoclonal BrdUrd antibodies, the DNA was partially denatured by incubating the cells in $2.0 \mathrm{M} \mathrm{HCl}$ at $37^{\circ} \mathrm{C}$. After neutralization, cells were incubated with primary anti-BrdUrd monoclonal antibodies (M744, Dako). Secondary fluorescein isothiocyanate-conjugated antibodies (F313, Dako) were used to detect the primary antibodies. The double-stranded regions of DNA were then stained with propidium iodide (Sigma-Aldrich Co.). The cells were analyzed with respect to relative DNA content (red fluorescence) and BrdUrd content (green fluorescence) in a Cytograph System50-H flow cytometer (Ohio Instruments, Westwood, MA). For the computer analysis, Multi2D and Multicycle software programs (Phoenix Flow Systems, San Diego, CA) were used. The data were analyzed and calculations made as described previously (Fredlund and Oredsson, 1997).

\section{Western Blot Analysis}

Cells for Western blot analysis were harvested by trypsinization, counted in a hemocytometer, and pelleted at $700 \times g$ for $10 \mathrm{~min}$ at $4^{\circ} \mathrm{C}$. The cells were diluted in sample buffer (300 $\mu \mathrm{L}$ per $10^{6}$ cells, $62.5 \mathrm{mM}$ Tris-HCl, pH 6.8, 20\% glycerol, $2 \%$ SDS, $5 \%$-mercaptoethanol), sonicated, and heated at $95^{\circ} \mathrm{C}$ for 6 min and put on ice immediately thereafter. Aliquots containing 50,000 cells were loaded in the wells of precast SDS polyacrylamide gels (12\%; Invitrogen Life Technologies Inc., Carlsbad, CA). Note that loading was based on cell counting. Electrophoresis was performed in XCell Surelock MiniCell electrophoresis system and subsequent blotting by using the XCell blot module from Invitrogen Life Technologies Inc. The membranes were then blocked with $5 \%$ dry milk in $0.05 \%$ Tween-20 in PBS for detection of total protein levels or $5 \%$ BSA in $0.05 \%$ Tween- 20 in PBS for detection of phosphorylated proteins before overnight incubation with the primary antibody. Antibodies against human cyclin A2 (554175), human cyclin B1 (554176), and human cyclin D1 (554180) were purchased from BD PharMingen (San Diego, CA). The antibody against human cyclin E1 (sc-247) was purchased from Santa Cruz Biotechnology Inc. (Santa Cruz, CA). Antibodies against ERK1/2 (ab5430) and phosphorylated ERK1/2 (ab50011) were purchased from Abcam (Cambridge, UK). Horseradish peroxidase-conjugated goat anti-mouse immunoglobulin was used as a secondary antibody (P0447, Dako). The advanced ECL protein detection reagent was used according to the manufacturer's protocol (Amersham Biosciences Ltd., Buckinghamshire, UK). The ChemiDoc XRS system (Bio-Rad Inc., Hercules, CA) was used for the imaging and the software Quantity One (Bio-Rad Inc.) was used for the analysis of the bands. Bands were calculated as 


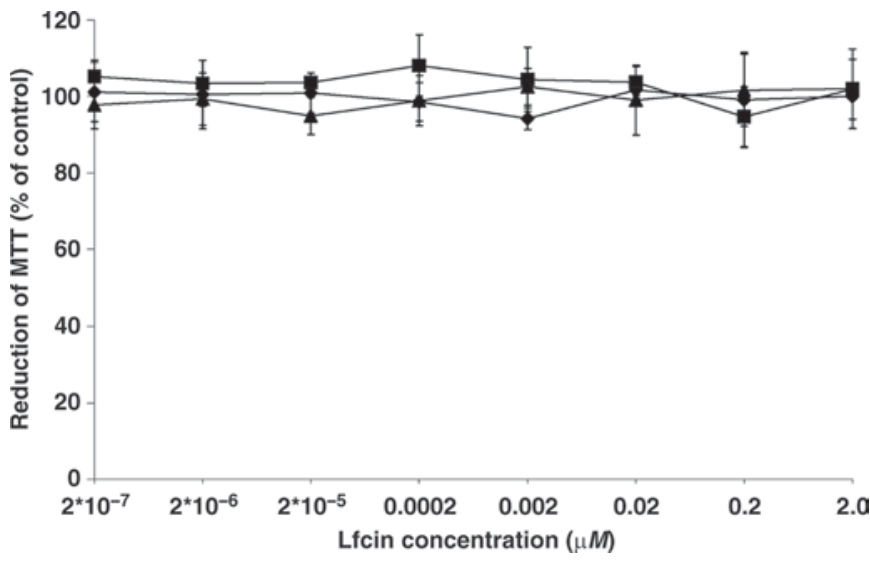

Figure 2. Effects of lactoferricin (Lfcin) treatment on CaCo-2 cells. Twenty-four hours after seeding of cells in 96-well plates, Lfcin was added at the final concentrations shown in the figure. At $24(\bullet), 48$ $(\boldsymbol{\square})$, and 72 hours $(\boldsymbol{\Delta})$ of growth, the effect of Lfcin was evaluated by determining the mitochondrial activity using a 3-(4,5-dimethylthiazol2-yl)-2,5-diphenyl tetrazolium bromide (MTT) assay. Symbols represent mean values and bars \pm SEM for $\mathrm{n}=18$ from 3 independent experiments.

percentage of control; for ERK1/2 and phosphorylated ERK1/2, the relationship of the 42 and $44 \mathrm{kDa}$ bands were calculated.

\section{Effect of Long-Term Treatment}

This experiment was designed to study the effect of Lfcin on cancer cell proliferation over a longer period. For the experiment, several replicate cultures, consisting of $0.5 \times 10^{6}$ cells were seeded in $5 \mathrm{~mL}$ of medium in $25-\mathrm{cm}^{2}$ cell culture flasks. Cells were seeded in the absence or presence of 0.02 or $0.2 \mu M$ Lfcin; triplicates of each treatment were used. At each passage, cells were harvested by trypsinization, counted in a hemocytometer, and reseeded at the same density as above. The cells received the same treatment during each passage. The data are presented as total amount of cells that would accumulate if all cells had been reseeded at each passage. These calculations were based on the number of population doubling times at each passage. The experiment was repeated twice.

\section{Data Analysis and Statistical Analysis}

Two-tailed unpaired Student's $t$-test was used for the statistical evaluation of significance. Regression analysis was used to determine the length of the $G_{2}+M$ phase. Statistical analyses were performed in Microsoft Office Excel 2003 (Seattle, WA).

\section{RESULTS}

\section{Cytotoxicity}

The MTT assay is assumed to reflect cell number and is used to construct dose-response curves. Figure 2 shows the reduction of MTT as percentage of control (on the y-axis) as a result of the Lfcin concentration (on the $\mathrm{x}$-axis) after 24,48 , and $72 \mathrm{~h}$ of Lfcin treatment. The MTT assay did not reveal any adverse effect of Lfcin treatment on MTT reduction. Thus, Lfcin treatment at the doses used did not result in cell death.

\section{Cell Proliferation}

Based on the results from the MTT assay combined with knowledge about the possible physiological levels of Lfcin in the human gut, we decided to use concentrations of $0.02,0.2$, and $2.0 \mu \mathrm{M}$ Lfcin in the proliferation studies. Treatment with Lfcin did not appear to affect cell proliferation during the experimental period (Figure 3). However, small effects on a specific cell cycle phase would not be apparent in this short growth-curve experiment.

\section{Effect of Lfcin Treatment on S Phase Length}

Next, we studied the effect of Lfcin treatment on cell cycle kinetics. Small but prominent effects that may not show in cytotoxicity tests and short growth-curve experiments may be revealed by studying the length of the different cell cycle phases using a BrdUrd DNA flow cytometric method (Fredlund and Oredsson, 1997; Nasizadeh et al., 2005). The data in Table 1 show that

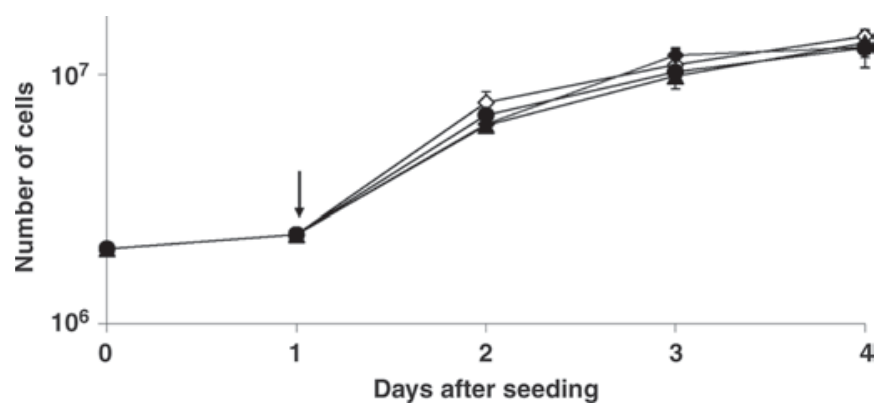

Figure 3. Growth curves showing the effect of lactoferricin (Lfcin) treatment on CaCo-2 cell proliferation. Twenty-four hours after seeding of cells in Petri dishes (arrow), Lfcin was added to achieve final concentrations of $2.0(\bullet), 0.02(\mathbf{\Delta})$ or $0.0002(\bullet) \mu M$ Lfcin; PBS was added to the control cells $(\diamond)$. Cells were counted in a hemocytometer to determine the total cell number. Symbols represent means and bars \pm SEM for $\mathrm{n}=5$ from 2 independent experiments. When not visible, bars are covered by the symbol. 
A

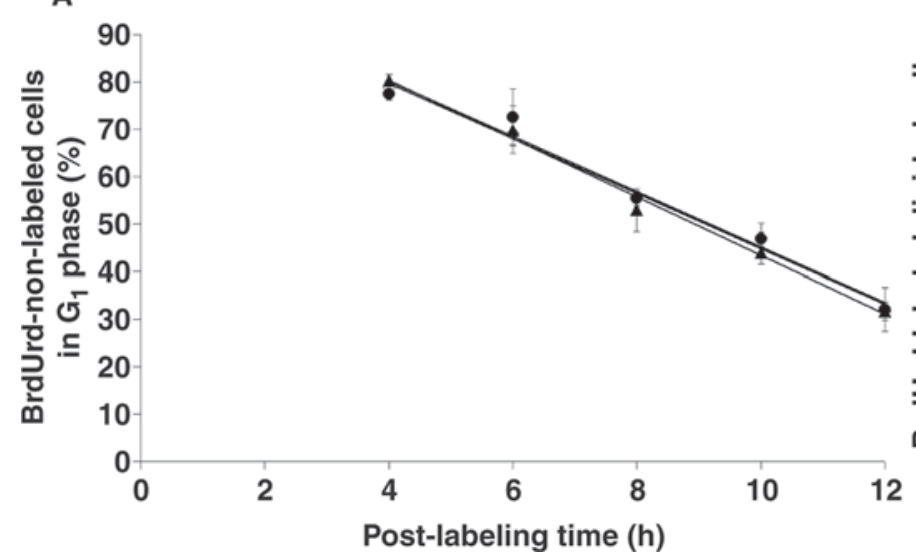

B

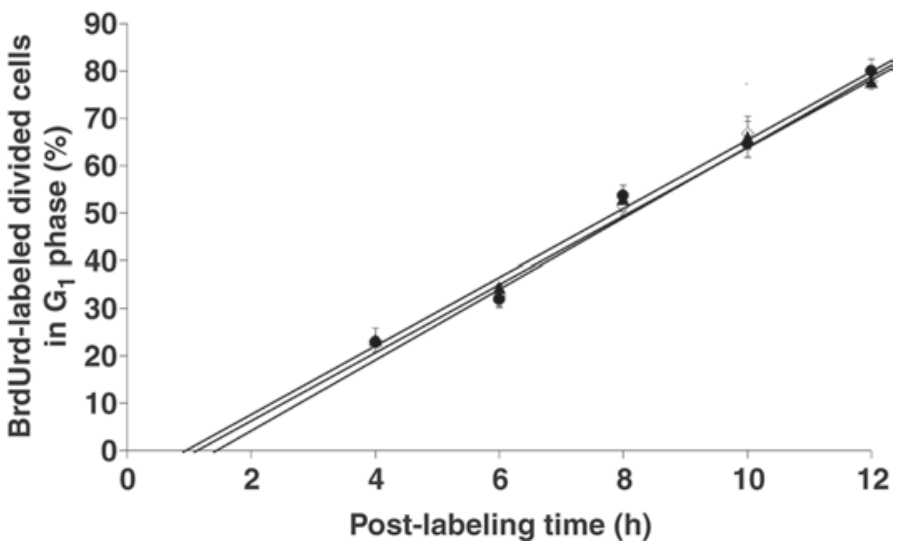

Figure 4. Lactoferricin (Lfcin) treatment did not affect the rate of $\mathrm{G}_{1} / \mathrm{S}$ transition or the length of $\mathrm{G}_{2}+\mathrm{M}$ phase in CaCo- 2 cells. The length of the different cell cycle phases were studied with a bromodeoxyuridine (BrdUrd)-DNA flow cytometric method. Subconfluent cultures were reseeded at a low density. Twenty-four hours after seeding, Lfcin was added to achieve the final concentrations of $2.0(\bullet)$ or $0.02(\boldsymbol{\Delta}) \mu M$; control $(\diamond)$ received PBS. Cells were labeled with BrdUrd after $48 \mathrm{~h}$ of Lfcin treatment. After a 30-min labeling period, the BrdUrd-containing medium was removed and cells were allowed to progress through the cell cycle in BrdUrd-free medium. Cells were collected for flow cytometry-mediated analysis of the DNA and BrdUrd contents at various times post-labeling. The percentage of BrdUrd-non-labeled cells in the $\mathrm{G}_{1}$ phase was plotted on the $\mathrm{y}$-axis against post-labeling time on the $\mathrm{x}$-axis $(\mathrm{A})$. The slope of each line indicates the rate of $\mathrm{G}_{1} / \mathrm{S}$ transition: the steeper the line, the higher the rate of $\mathrm{G}_{1} / \mathrm{S}$ transition. The data were fit by regression analysis. The percentage of BrdUrd-labeled cells in the $\mathrm{G}_{1}$ phase was plotted on the $\mathrm{y}$-axis against post-labeling time on the $\mathrm{x}$-axis (B). The intercepts of the lines with the $\mathrm{x}$-axis is a measure of the length of the $\mathrm{G}_{2}+\mathrm{M}$ phase. Values are mean $\pm \mathrm{SD}$ for $\mathrm{n}=3$. When not visible, bars are covered by the symbol.

treatment with $2.0 \mu M$ Lfcin for 48 and $72 \mathrm{~h}$ resulted in a significantly prolonged $\mathrm{S}$ phase. Treatment with $0.02 \mu M$ Lfcin showed a trend toward increased S phase length but it was not statistically significant. In cells treated with $2.0 \mu M$ Lfcin, the S phase was prolonged $10 \%$ compared with control.

\section{Effect of Lfcin Treatment on the Rate of $G_{1} / S$ Transition}

The rate of $G_{1} / S$ transition was studied by investigating the movement of BrdUrd-non-labeled cells from $\mathrm{G}_{1}$ into $\mathrm{S}$ phase (Fredlund and Oredsson, 1997; Nasizadeh et al., 2005; Figure 4A). The figure shows the percentage decrease in the $G_{1}$ phase population, which is inversely correlated to the increase in the $\mathrm{S}$ phase population. The slopes of the lines indicate the rate of $\mathrm{G}_{1} / \mathrm{S}$ transition; that is, the steeper the line, the higher the rate of $\mathrm{G}_{1} / \mathrm{S}$ transition. When no cells are entering $\mathrm{S}$ phase, the line is horizontal. The rate of the $\mathrm{G}_{1} / \mathrm{S}$ transition was not affected at $48 \mathrm{~h}$ of Lfcin treatment in $\mathrm{CaCo}-2$ cells.

\section{Effect of Lfcin Treatment on the Length of the $G_{2}+M$ Phase}

During the post-labeling time, BrdUrd-labeled cells will progress through the $\mathrm{G}_{2}+\mathrm{M}$ phase and into the $\mathrm{G}_{1}$ phase of the next cell cycle. The BrdUrd-labeled cells appear in $G_{1}$ phase when the minimum period for
$\mathrm{G}_{2}+\mathrm{M}$ phase has passed. The percentage of BrdUrdlabeled divided cells in relation to the total number of BrdUrd-labeled cells was plotted in a graph to calculate the length of the $\mathrm{G}_{2}+\mathrm{M}$ phase (Fredlund and Oredsson, 1997; Nasizadeh et al., 2005; Figure 4B). The intercept of the lines with the $\mathrm{X}$-axis is a measure of the length of the $\mathrm{G}_{2}+\mathrm{M}$ phase. The length of the $\mathrm{G}_{2}+\mathrm{M}$ phase in the CaCo-2 cells was not affected after $48 \mathrm{~h}$ of Lfcin treatment.

Table 1. Length of the $\mathrm{S}$ phase $\left(\mathrm{T}_{\mathrm{S}}\right)$ in CaCo-2 cells grown for 24,48 , or $72 \mathrm{~h}$ in the absence or presence of 0.02 or $2.0 \mu \mathrm{M}$ lactoferricin ${ }^{1}$

\begin{tabular}{lccc}
\hline Item & Control & $0.02 \mu M$ & $2.0 \mu M$ \\
\hline $24 \mathrm{~h}^{2}$ & & & \\
$\mathrm{~T}_{\mathrm{S}}(\mathrm{h})$ & $12.1 \pm 0.7$ & $12.2 \pm 1.6$ & $13.1 \pm 0.8^{*}$ \\
$\mathrm{~T}_{\mathrm{S}}(\%$ of control) & 100 & 101 & 108 \\
$48 \mathrm{~h}^{3}$ & & & \\
$\mathrm{~T}_{\mathrm{S}}(\mathrm{h})$ & $10.3 \pm 0.9$ & $10.8 \pm 0.5$ & $11.3 \pm 1.1^{*}$ \\
$\mathrm{~T}_{\mathrm{S}}(\%$ of control) & 100 & 105 & 110 \\
$72 \mathrm{~h}^{2}$ & & & \\
$\mathrm{~T}_{\mathrm{S}}(\mathrm{h})$ & $11.4 \pm 0.7$ & $11.6 \pm 0.7$ & $12.4 \pm 0.3^{*}$ \\
$\mathrm{~T}_{\mathrm{S}}(\%$ of control$)$ & 100 & 102 & 109 \\
\hline
\end{tabular}

${ }^{1}$ Cells were seeded and treated as described in the caption of Figures 4 and $5 ; \mathrm{T}_{\mathrm{S}}$ was calculated as described previously (Fredlund and Oredsson, 1997). For the statistical evaluation, Student's unpaired $t$ test was used.

${ }^{2} \mathrm{n}=3$ from 1 experiment (mean $\left.\pm \mathrm{SD}\right)$.

${ }^{3} \mathrm{n}=10$ from 2 independent experiments (mean $\pm \mathrm{SD}$ ).

$* P<0.05$ compared with control. 
A

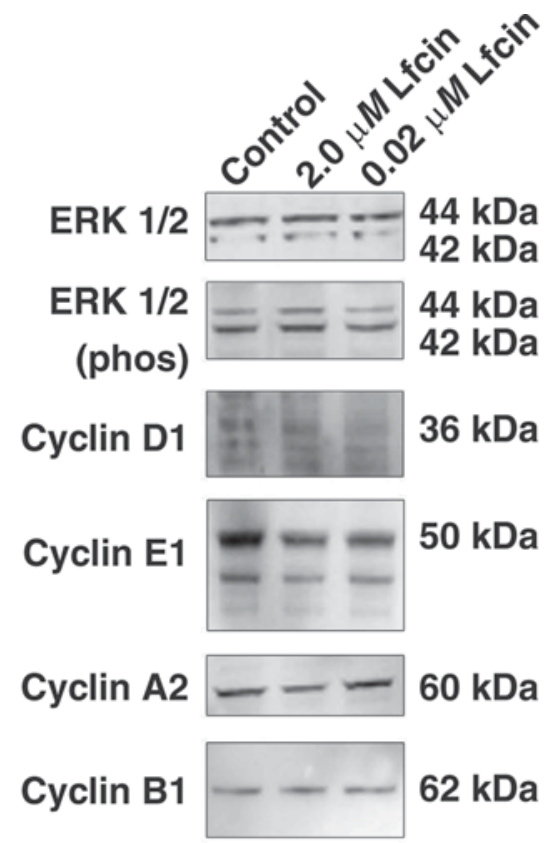

B

\begin{tabular}{lcccc}
\hline & $\mathbf{2 . 0} \mu M$ Lfcin & $\mathbf{4 4} \mathbf{k D a} / \mathbf{4 2} \mathbf{k D a}$ & $\mathbf{0 . 0 2} \mu M$ Lfcin & $\mathbf{4 4} \mathbf{k D a} / \mathbf{4 2} \mathbf{~ k D a}$ \\
\hline ERK 1/2 & & & & \\
$44 \mathrm{kDa}$ & $95.2 \pm 9.0^{*}$ & 2.2 & $101.9 \pm 15.8$ & 1.8 \\
$42 \mathrm{kDa}$ & $97.8 \pm 65.0$ & & $112.0 \pm 35.0$ & \\
\hline Phos ERK 1/2 & & & & \\
$44 \mathrm{kDa}$ & $87.2 \pm 12.4$ & 0.6 & $83.6 \pm 7.0^{*}$ & 0.5 \\
$42 \mathrm{kDa}$ & $84.5 \pm 13.2$ & & $83.2 \pm 7.3^{*}$ & \\
\hline Cyclin D1 & & & \\
$36 \mathrm{kDa}$ & $69.8 \pm 32.4$ & & $78.4 \pm 24.5$ & \\
\hline Cyclin E1 & & & \\
$50 \mathrm{kDa}$ & $60.5 \pm 12.3^{*}$ & & $101.0 \pm 4.1$ & \\
\hline Cyclin A2 & & & \\
$60 \mathrm{kDa}$ & $98.0 \pm 3.2$ & & \\
\hline Cyclin B1 & & & \\
$62 \mathrm{kDa}$ & $126 \pm 61$ & &
\end{tabular}

Figure 5. Effect of lactoferricin (Lfcin) treatment on various cell cycle regulatory proteins in CaCo-2 cells. Twenty-four hours after seeding of cells in Petri dishes, Lfcin was added to achieve final concentrations of 2.0 or $0.02 \mu M$; control received PBS. Cells were harvested after $48 \mathrm{~h}$ of Lfcin treatment. Western blot analysis was used to detect the different proteins (A). The intensities of the bands are presented as percentage of control (B). The relationship between the $44 \mathrm{kDa}$ band and the $42 \mathrm{kDa}$ band [for extracellular signal-regulated kinase-1/2 (ERK1/2) and phosphorylated ERK1/2] was calculated. The ratio of $44 \mathrm{kDa} / 42 \mathrm{kDa}$ in the control cells was 2.0 for ERK1/2 and 0.6 for phosphorylated ERK1/2. ${ }^{*} P<0.05$ compared to control. The data are representative of 3 independent cultures from 2 independent experiments.

\section{Western Blot}

As Lfcin treatment caused cell cycle kinetic effects, we studied the levels of some proteins involved in cell cycle regulation. Our interpretation of the data is based on 3 independent experiments. The level of the nonphosphorylated ERK1/2 $44 \mathrm{kDa}$ protein was higher than the level of the $42 \mathrm{kDa}$ protein; however, the 42 $\mathrm{kDa}$ band was more phosphorylated (Figure 5A).

The protein levels, as well as the ratio between the 2 bands, remained unchanged in cells grown in the presence of Lfcin compared with control cells (Figure 5B). The level of cyclin D1 was not significantly affected by Lfcin treatment although the data indicate a trend of decreased cyclin D1 in Lfcin-treated cells. In addition to the full-length cyclin E1, a low-molecular-weight band was found. Treatment with $2.0 \mu M$ Lfcin for 48 $\mathrm{h}$ resulted in a significantly decreased cyclin E1 level compared with control. Treatment with $0.02 \mu M$ Lfcin also resulted in a decreased cyclin E1 level although it was not significant. The cyclin A2 and B1 levels were not affected by the Lfcin treatment.

\section{Long-Term Treatment}

People who consume milk and dairy products ingest a small dose of milk proteins and bioactive peptides each day. Even though the immediate results are very small, there may be a significant influence over time. To gain understanding of the long-term effects of Lfcin on human colon cancer cells, we grew the cells in the presence of Lfcin for 9 passages ( $5 \mathrm{wk}$ ). Figure 6 shows that the accumulated cell number was significantly lower for cells treated with 0.2 or $0.02 \mu M$ Lfcin over 9 cell passages compared with the untreated control cells. In cultures treated with 0.2 or $0.02 \mu M$ Lfcin, the cell numbers were 13 and $35 \%$ of control, respectively, after 5 wk of treatment.

\section{DISCUSSION}

The full extent of biologically active components in our diet is unknown, and our understanding of their mechanisms of action is even more limited (Petricoin and Liotta, 2003). The role of proteins and peptides as physiologically active factors in the diet is being increasingly acknowledged. Environmental factors such as food and physical activity have an important influence on the risk of cancer, especially as these factors can be modified by a change in behavior (World Cancer Research Fund/American Institute for Cancer Research, 2007). Delayed cancer development may be obtained by a change in eating habits and thus it is important to define such changes.

Different food components such as dietary agents from fruit and vegetables have been shown to exert effects on the cyclins and cdks controlling the cell cycle (Meeran and Katiyar, 2008). Also, green and black tea polyphenols have shown anticancer effects on their own and in combination with bovine milk proteins (Mohan et al., 2007). Studies of polyphenols, which are com- 
monly found in fruits and vegetables as well as in wine and tea, have shown a link to lower incidence of colon cancer (Flood et al., 2002). Strawberries, which are high in several antioxidants, have been shown to decrease the rate of proliferation in human colon cancer cells (Olsson et al., 2006). Epidemiological studies have revealed a significant connection between whole grain consumption and reduced colon cancer incidence (Chatenoud et al., 1998). Ferulic acid (FA) and para-coumaric acid $(\boldsymbol{p}$-CA) are common constituents of whole-grain cereals. The effects of FA and $p$-CA on metabolic activity, proliferation, and cell cycle kinetics in the CaCo-2 cell line have been investigated with the same techniques used in our study. Ferulic acid and $p$-CA slowed down proliferation of Caco-2 cells, and FA treatment resulted in a prolongation of the S phase (Janicke et al., 2005).

A large amount of data regarding the bioactive functions of food components have been obtained using cell lines, and an important question regarding much of this work is the relevance of the concentrations used (Petricoin and Liotta, 2003; Davis and Milner, 2004). Considering the equimolar relation between Lf and Lfcin and the knowledge that a major part of ingested Lf survives passage through the gut (Troost et al., 2001), concentrations in our study were chosen within a span equivalent to daily intake of 0.05 to $2.0 \mathrm{~L}$ of milk or dairy products.

Our study clearly shows that Lfcin treatment significantly, albeit slightly, prolonged the S phase in CaCo-2 cells. However, the results did not reveal any effect on the length of the $G_{2}+M$ phase or on the rate of $G_{1} / S$ transition. Thus, Lfcin treatment only resulted in a very small effect on cell cycle progression, which did not give any obvious effect in the short-term growth curve experiment. However, small effects on the progression of the cell cycle may be highly significant over a longer time span. The long-term treatment study was initiated to investigate such a hypothesis. Indeed, we found that Lfcin treatment for 5 wk delayed cell proliferation significantly compared with control. The long-term treatment experiment was designed to mimic the effects of normal milk consumption on cells of the intestine. Physiologically relevant doses; that is, doses within the span achieved by daily consumption of about $0.2 \mathrm{~L}$ of milk or fluid milk products, were used. In normal cells, a prolonged $\mathrm{S}$ phase may result in improved DNA repair, which decreases the probability of development of intestinal cancer. A slight prolongation of the cell cycle induced by food components may also, in the long-term, reduce cancer risk because cancer development is dependent on the rate of cell proliferation. When a cancer has developed, it is beneficial that food components can slow the rate of tumor growth. These

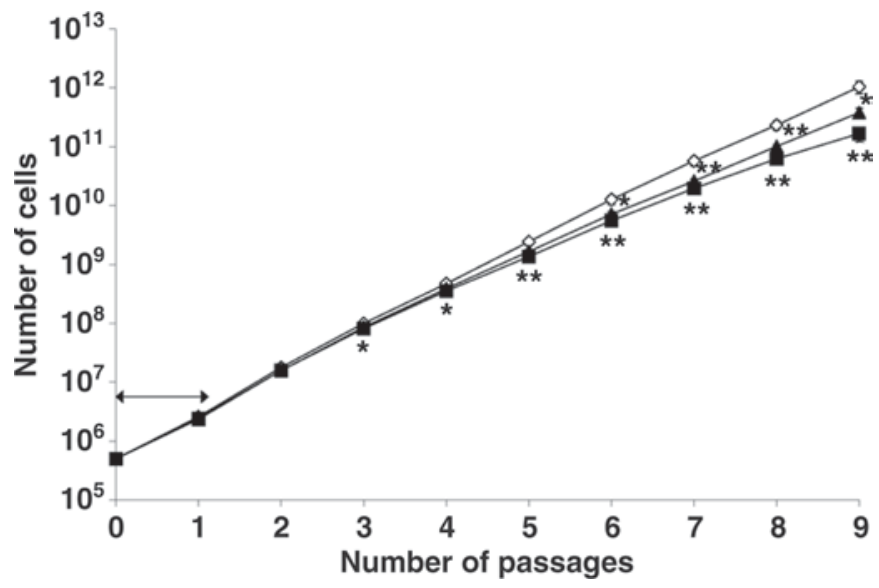

Figure 6. Long-term treatment with lactoferricin (Lfcin) resulted in decreased cell proliferation in CaCo- 2 cells. The accumulated cell number on the $\mathrm{y}$-axis versus number of passages on the $\mathrm{x}$-axis shows that the cell number was significantly lower for cells treated with 0.2 (ם) or $0.02(\boldsymbol{\Delta}) \mu M$ Lfcin during 9 cell passages (5 wk) compared with the untreated control cells $(\diamond)$. The period in which cell cycle kinetics were studied is indicated by the two-headed arrow. Values are mean values $\pm \mathrm{SD}$ for $\mathrm{n}=6$ from 2 independent experiments. When not visible, bars are covered by the symbol. ${ }^{* *} P<0.01$ and ${ }^{*} P<0.05$ compared with control.

hypotheses, of course, have to be tested in animal experimental systems.

Cell cycle kinetics are usually discussed in connection with cell cycle regulatory proteins. Hence, we decided to study the expression of some cell cycle regulatory proteins as a start to unravel the molecular mechanisms behind our findings. The findings from the cell cycle kinetic data are supported by lowered levels of cyclin E1, which is expressed during late $\mathrm{G}_{1}$ phase and early S phase (Möröy and Geisen, 2004). Cyclin E1, in complex with its kinase subunit $\mathrm{cdk} 2$, regulates several proteins necessary for $\mathrm{G}_{1} / \mathrm{S}$ transition, and a decreased expression of cyclin E1 may cause lower levels of these proteins, which in turn would explain the prolongation of the $\mathrm{S}$ phase.

\section{CONCLUSIONS}

The level of Lfcin achieved in the intestine by milk consumption significantly prolonged the $\mathrm{S}$ phase but did not affect the length of the $\mathrm{G}_{2}+\mathrm{M}$ phase or the rate of $\mathrm{G}_{1} / \mathrm{S}$ transition in human $\mathrm{CaCo}-2$ colon cancer cells. The small but significant prolongation of the $\mathrm{S}$ phase resulted in a remarkable reduction of cell number when the treatment occurred for a long period. We hypothesize that this reduction in the rate of cell proliferation may be part of reducing the risk of cancer by milk consumption. The hypothesis needs to be tested in animal experiments. 


\section{ACKNOWLEDGMENTS}

We thank Ewa Dahlberg (Department of Cell and Organism Biology, Lund University) for expert technical assistance. We also thank Bo Baldetorp for the use of the flow cytometer at the Department of Oncology, Lund University (Lund, Sweden). This work was supported by grants from The Swedish Research Council for Environment, Agricultural Sciences, and Spatial Planning (FORMAS), Sweden.

\section{REFERENCES}

Baserga, R., and F. Wiebel. 1969. The cell cycle of mammalian cells. Int. Rev. Exp. Pathol. 7:1-30.

Bellamy, W., M. Takase, K. Yamauchi, H. Wakabayashi, K. Kawase, and M. Tomita. 1992. Identification of the bactericidal domain of lactoferrin. Biochim. Biophys. Acta 1121:130-136.

Chatenoud, L., A. Tavani, C. L. Vecchia, D. R. Jacobs, E. Negri, F. Levi, and S. Franceschi. 1998. Whole grain food intake and cancer risk. Int. J. Cancer 77:24-28.

Cho, E., S. A. Smith-Warner, and D. Spiegelman. 2004. Dairy foods, calcium, and colorectal cancer: A pooled analysis of 10 cohort studies. J. Natl. Cancer Inst. 96:1015-1022.

Davis, C. D., and J. Milner. 2004. Frontiers in nutrigenomics, proteomics, metabolomics and cancer prevention. Mutat. Res. 551:51-64.

Denizot, F., and R. Lang. 1986. Rapid colorimetric assay for cell growth and survival. Modifications to the tetrazolium dye procedure giving improved sensitivity and reliability. J. Immunol. Methods $89: 271-277$.

Dolbeare, F., H. Gratzner, M. G. Pallavicini, and J. W. Gray. 1983. Flow cytometric measurement of total DNA content and incorporated bromodeoxyuridine. Proc. Natl. Acad. Sci. USA 80:5573-5577.

Flood, A., E. M. Velie, N. S. Chaterjee, F. Amy, F. E. Thompson, and J. V. Lacey. 2002. Fruit and vegetable intakes and the risk of colorectal cancer in the breast cancer detection demonstration project follow-up cohort. Am. J. Clin. Nutr. 75:936-943.

Fredlund, J. O., M. Johansson, B. Baldetorp, and S. M. Oredsson. 1994. Abnormal DNA synthesis in polyamine deficient cells revealed by bromodeoxyuridine-flow cytometry technique. Cell Prolif. 27:243-256.

Fredlund, J. O., and S. M. Oredsson. 1997. Ordered cell cycle phase perturbations in Chinese hamster ovary cells treated with an $S$-adenosylmethionine decarboxylase inhibitor. Eur. J. Biochem. 249:232-238.

Gill, H. S., F. Doull, K. J. Rutherfurd, and M. L. Cross. 2000. Immunoregulatory peptides in bovine milk. Br. J. Nutr. 84(Suppl. 1):S111-S117.

Holst, C. M., and S. M. Oredsson. 2005. Comparison of three cytotoxicity tests in the evaluation of the cytotoxicity of a spermine analogue on human breast cancer cell lines. Toxicol. In Vitro 19:379-387.

Janicke, B., G. Onning, and S. M. Oredsson. 2005. Differential effects of ferulic acid and $p$-coumaric acid on $\mathrm{S}$ phase distribution and length of S phase in human colonic cell line Caco-2. J. Agric. Food Chem. 53:6658-6665.

Johnson, D. G., and C. L. Walker. 1999. Cyclins and Cell cycle. Annu. Rev. Pharmacol. Toxicol. 39:295-312.

Korhonen, H., and A. Pihlanto. 2006. Bioactive peptides: Production and functionality. Int. Dairy J. 16:945-960.

Kuwata, H., T.-T. Yip, M. Tomita, and T. W. Hutchens. 1998. Direct evidence of the generation in human stomach of an antimicrobial peptide domain (lactoferricin) from ingested lactoferrin. Biochim. Biophys. Acta 1429:129-141.

Levay, P. F., and M. Viljoen. 1995. Lactoferrin: A general review. Haematologia (Budap.) 80:252-267.

Mader, J. S., A. Richardson, J. Salsman, D. Top, R. de Antueno, R. Duncan, and D. W. Hoskin. 2007. Bovine lactoferricin causes apoptosis in Jurkat T-leukemia cells by sequential permeabilization of the cell membrane and targeting of mitochondria. Exp. Cell Res. 313:2634-2650.

Meeran, S. M., and S. K. Katiyar. 2008. Cell cycle control as a basis for cancer chemoprevention through dietary agents. Front. Biosci. 13:2191-2202

Min, S., and J. Krochta. 2005. Inhibition of Penicillium commune by edible whey protein films incorporating lactoferrin, lactoferrin hydrolysate, and lactoperoxidase systems. J. Food Sci. 70:87-94.

Mohan, K. V. P. C., P. Gunasekaran, E. Varalakshmi, Y. Hara, and S. Nagini. 2007. In vitro evaluation of the anticancer effect of lactoferrin and tea polyphenol combination on oral carcinoma cells. Cell Biol. Int. 31:599-608

Möröy, T., and C. Geisen. 2004. Cyclin E. Int. J. Biochem. Cell Biol. $36: 1424-1439$

Mosmann, T. 1983. Rapid colorimetric assay for cellular growth and survival: application to proliferation and cytotoxicity assays. J Immunol. Methods 65:55-63.

Nasizadeh, S., L. Myhre, L. Thiman, and S. M. Oredsson. 2005 Importance of polyamines in cell cycle kinetics as studied in a transgenic system. Exp. Cell Res. 308:254-264.

Norbury, C., and P. Nurse. 1992. Animal cell cycles and their control Annu. Rev. Biochem. 61:441-470.

Olsson, M. E., S. C. Anderson, S. M. Oredsson, R. H. Berglund, and K.-E. Gustavsson. 2006. Antioxidant levels and inhibition of cancer cell proliferation in vitro by extracts from organically and conventionally cultivated strawberries. J. Agric. Food Chem. $54: 1248-1255$

Perdigon, G., A. De Moreno de LeBlanc, J. Valdez, and M. Rachid 2002. Role of yoghurt in the prevention of colon cancer. Eur. J. Clin. Nutr. 56:65-68.

Petricoin, E., and L. Liotta. 2003. Clinical applications of proteomics. J. Nutr. 133:2476-2484.

Shaul, Y. D., and R. Seger. 2007. The MEK/ERK cascade: From signaling specificity to diverse functions. Biochim. Biophys. Acta 1773:1213-1226.

Troost, F. J., J. Steijns, W. H. M. Saris, and R.-J. M. Brummer. 2001 Gastric digestion of bovine lactoferrin in vivo in adults. J. Nutr. 131:2101-2104

Van Belzen, N. 2002. The role of lactoferrin in cancer prevention. Sci. Aliments 22:461-465.

Wakabayashi, H., M. Takase, and M. Tomita. 2003. Lactoferricin derived from milk protein lactoferrin. Curr. Pharm. Des. 9:12771287.

Wakabayashi, H., K. Yamauchi, and M. Takase. 2006. Lactoferrin research, technology and applications. Int. Dairy J. 16:12411251

World Cancer Research Fund/American Institute for Cancer Research. 2007. Food, Nutrition, Physical Activity and the Prevention of Cancer: a Global Perspective. AICR, Washington, DC.

Yamaguchi, T., M. Yamauchi, T. Sugimoto, D. Chauhan, K. C. Anderson, E. M. Brown, and K. Chihara. 2002. The extracellular calcium $\left(\mathrm{Ca}^{2+}\right)$-sensing receptor is expressed in myoloma cells and modulates cell proliferation. Biochem. Biophys. Res. Commun. 299:532-538.

Yoo, Y. C., S. Watanabe, R. Watanabe, K. Hata, K. Shimazaki, and I. Azuma. 1997. Bovine lactoferrin and lactoferricin, a peptide derived from bovine lactoferrin, inhibit tumor metastasis in mice. Jpn. J. Cancer Res. 88:184-190. 